\title{
The Design of a Low Frequency Calibration Shaking Table
}

\author{
Lina Cheng ${ }^{1}$, Hongjiang Chen ${ }^{2}$, Lixin $\mathrm{Li}^{1}$, Juan Meng ${ }^{1}$ and Jianxian Cai ${ }^{1}$ \\ ${ }^{1}$ Institute of Disaster Prevention, Sanhe Hebei, China, 065201; \\ ${ }^{2}$ Institute of Metrology and Test, Changsha, Hunan, 410014. \\ cln_83@163.com,15081692304@163.com, lilixin4job@163.com, \\ mengjuan@cidp.edu.cn,42356203@qq.com
}

\begin{abstract}
The design of a low frequency calibration shaking table is introduced in this paper. First, we confirm the design specification of low frequency calibration environment of vibration specification, we choose shaking sensor. Then, the design of the relative velocity feedback analyzes this method in detail and carry out the simulation table according to the national standard and the deployment a vibration exciter is introduced. According to the design method as the control method of the shaking table. We did simulation and calculation. Finally, we test the amplitude versus frequency response characteristics and distortion under the situation of open loop and closed loop. The results show that the low frequency movement signal of low frequency shaking table is improved and it can meet the requirement of the calibration of low frequency vibration sensor.
\end{abstract}

Keywords: Low Frequency Shaking Table; Low Frequency Calibration; Relative Velocity Feedback

\section{Introduction}

Vibration is a kind of common physical phenomenon, existing in many engineering fields widely. We need to use the vibration equipment measuring vibration in order to research the vibration problem. And for purpose of guaranteeing the accuracy of the vibration measurement results, we need to calibrate the instrument. Vibration calibration is aimed to obtain accurate measurement results by using these sensors, within the scope of the amplitude and frequency to determine its calibration coefficient (sensitivity).

Vibration calibration is accomplished in the vibration calibration instrument, vibration calibration instrument usually consists of two parts: calibration shaking table and measuring system. The function of calibration shaking table is to provide the calibration excitation signal. This paper introduces the design of a low frequency calibration shaking table.

\section{The Design Requirements of Low Frequency Calibration Shaking Table}

Low frequency calibration shaking table is the source of vibration calibration and the key instrument for it. According to different occasions and requirements, low frequency calibration shaking table is diverse obviously .For example, exciting force ranges from more than $10 \mathrm{~N}$ to more than $100 \mathrm{~N}$, and the range is from a few millimeters to hundreds of $\mathrm{mm}$.

In the view of the current shaking sensor's calibration requirements, large vibration forces and ranges of low frequency calibration shaking table has technical advantages could obtain low frequency motion signal with higher SNR, but this kind of vibration 
table is complex in technology, expensive in manufacture, cost-higher in maintenance. So state-level or larger industries usually have demand on this kind of equipment.

On the contrary, small size low frequency calibration shaking table can meet the need of general department for calibrating that is moderate in cost and technology and relatively simple in maintenance, and also satisfies the calibration need. Ultimately the purpose of scientific research to serve the application. In this paper, the actual design of small scale low frequency shaking table that has many advantages in addition to the scientific research, tries to make the vibration meet the general measuring mechanism and vibration equipment manufacturers' requirements.

Design specifications as shown in table 1.

Table 1. Technical Specification of Small Scale Low Frequency Shaking Table

\begin{tabular}{|c|c|c|}
\hline Technical specification & Horizontal vibration table & Vertical vibration table \\
\hline \multirow{5}{*}{$\begin{array}{l}\text { Trip }(p-p) \\
\text { Exciting force } \\
\text { Table size } \\
\text { Maximum load } \\
\text { maximum bare table } \\
\text { acceleration }\end{array}$} & $20 \mathrm{~mm}$ & \\
\hline & $100 \mathrm{~N}$ & \\
\hline & $250 \mathrm{~mm} \times 230 \mathrm{~mm}$ & $230 \mathrm{~mm} \times 150 \mathrm{~mm}$ \\
\hline & $4 \mathrm{~kg}$ & \\
\hline & $20 \mathrm{~m} / \mathrm{s} 2$ & $10 \mathrm{~m} / \mathrm{s} 2$ \\
\hline $\begin{array}{l}\text { Total harmonic } \\
\text { distortion }\end{array}$ & $\leq 5 \%(0.5 \mathrm{~Hz}-100 \mathrm{~Hz})$ & \\
\hline speed & $\leq 5 \%(0.1 \mathrm{~Hz}-100 \mathrm{~Hz})$ & \\
\hline $\begin{array}{l}\text { The transverse acceleration, } \\
\text { bending and rocking }\end{array}$ & $\begin{array}{l}f \leq 10 \mathrm{~Hz} \text { 时 : } \leq 1 \% \\
10 \mathrm{~Hz}-100 \mathrm{~Hz}: \leq 10 \%\end{array}$ & $\begin{array}{l}f \leq 10 \mathrm{~Hz} \text { 时 : } \leq 3 \% \\
10 \mathrm{~Hz}-100 \mathrm{~Hz}: \leq 10 \%\end{array}$ \\
\hline $\begin{array}{ll}\text { Table noise } & f<10 \mathrm{~Hz} \\
& \mathrm{f} \geq 10\end{array}$ & $\begin{array}{l}\geq 40 \mathrm{~dB} \\
\geq 60 \mathrm{~dB}\end{array}$ & \\
\hline $\begin{array}{l}\text { Acceleration amplitude } \\
\text { stability }\end{array}$ & $\leq 0.1 \%$ & \\
\hline
\end{tabular}

Vibration table 's vibration forces and ranges are the two important indicators. Vibration forces influences the maximum acceleration of the vibrating table, and structural vibration under the excitation of the natural environment is not more than 10 to $3 \mathrm{~g}$ generally. In a strong earthquake acceleration amplitude is bigger, but it is generally not more than $2 \mathrm{~g}$. For example, 8.0 earthquake in Wenchuan, about 21 kilometers from the epicenter of the Wolongtai to obtain the maximum acceleration peak value is $0.976 \mathrm{~g}$ on strong earthquake records $[1,2]$. So low frequency calibration vibration table is designed according to the maximum of 1.0 to $2.0 \mathrm{~g}$ no-load acceleration, retaining a certain margin in the design. The actual maximum no-load acceleration may be better than design value. When Low-frequency vibration is calibrated, the motion signal SNR is a big problem. The range of the vibrating table is always limited, under the condition of the vibration table range, with the reduction of frequency,vibration table`s acceleration will be smaller, and the noise of the vibration table is a certain value. So the lowfrequency acceleration motion signal of vibration table is with often worse the SNR. There are three ways to improve the SNR: increasing range, reducing noise and filtering.

《The vibration and shock sensor calibration`s method section 21: comparison calibration \rangle$:$ in this paper requirements noise of vibration excitation equipment acuity in $20 \mathrm{db}$ (f $<10 \mathrm{~Hz}$ ), if the noise excitation equipment is $10-4 \mathrm{~m} / \mathrm{s} 2$. According to the requirements of $20 \mathrm{db}$, the need for the movement of the acceleration amplitude:

$$
a=10^{-4} \mathrm{~m} / \mathrm{s}^{2} \times 10^{\frac{20(\mathrm{~dB})}{20}}=10^{-3} \mathrm{~m} / \mathrm{s}^{2}
$$

The acceleration amplitude at $0.5 \mathrm{~Hz}$ amplitude for the corresponding movement 


$$
x=\omega^{2} \times a=9.86 \mathrm{~mm}
$$

Amplitude of shaking table movement displacement is designed to $10 \mathrm{~mm}$, peak to peak value of $20 \mathrm{~mm}$.

\section{The Design of Control System}

Low frequency shaking table needs reasonable control to get an accurate signal, In this paper the shaking table is designed by choosing relative-velocity feedback control technology. Relative speed feedback control is to increase the system damping, to expand the scope of speed flat section, to improve the distortion degree of low frequency signal. In order to extract the feedback, a relative velocity meter is designed.

The designed range low frequency calibration shaking table is $20 \mathrm{~mm}$, the movement of relative speedometer is $20 \mathrm{~mm}$ at least. Practically, in order to debug and to use easily, the movement of relative speedometer that should retain certain remainder follows $25 \mathrm{~mm}$ to design. Relative velocity meter obeying magnetoelectric principle, relies on coil that is installed in a magnetic fieldcutting lines of magnetic force to produce inductive electromotive force to measure movement signal on the table.

Relative velocity feedback principle as shown in figure 1 .

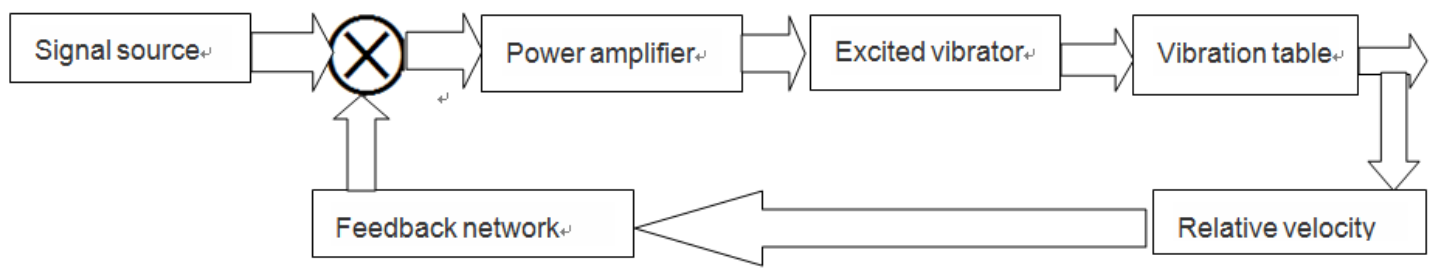

Figure 1. Relative Velocity Feedback Principle Diagram

If the signal source voltage is $u$, Magnification of power amplifier is KA, magnification of feedback network is Ks, electromechanical coupling coefficient of relative velocity meter is $\mathrm{G} 2$, vibration table`s movement displacement is $\mathrm{x}$, vibrator coil of excitation voltage is e.

$$
e=\left(u-K_{s} G_{2} s x\right) K_{A}
$$

The transfer function of the vibration table is [3]:

$$
\frac{x}{e}=\frac{G_{1}}{m L s^{3}+(b L+m R) s^{2}+\left(k L+b R+G_{1}^{2}\right) s+k R}
$$

In this formula, the quality of the vibration table about moving parts (including table, the excitation coil, table loading) is $m$, the viscous damping coefficient is $b$, stiffness of support spring is $\mathrm{k}$, the part of movement relative to the based displacement is $\mathrm{x}$, coupling coefficient of vibrator electromechanical is G1, resistance of coil is R, coil inductance is L. So we have:

$$
\begin{aligned}
\frac{x}{u}= & \frac{G_{1} K_{A}}{m L s^{3}+(b L+m R) s^{2}+\left(k L+b R+G_{1}^{2}+K_{s} K_{A} G_{1} G_{2}\right) s+k R} \\
& -x: \text { movement displacement of table; } \\
& -\quad \begin{array}{l}
u \text { : vibrator coil's resistance } \\
-G_{1}: \text { coupling coefficient of vibrator electromechanical }
\end{array}
\end{aligned}
$$


$-K_{A}$ : magnification of power amplifier

$m$ : the quality of the vibration table about moving parts

$L$ : coil inductance

$b$ : the viscous damping coefficient

$R$ : resistance of coil

$k:$ stiffness of support spring

$K_{B}$ : magnification of feedback network

$G_{2}$ : electromechanical coupling coefficient of relative velocity meter

Type (3) as the relative velocity feedback, the vibration table mathematical relationships. Assume that vibrator coil inductance is $0.25 \mathrm{H}$, transfer function is:

$$
\frac{x}{u}=\frac{146.2}{1.4 s^{3}+6.71 s^{2}+17982.6 s+3442.8}
$$

Acceleration amplitude-frequency characteristic curve of horizontal shaking table under open loop situation as shown in figure 2.

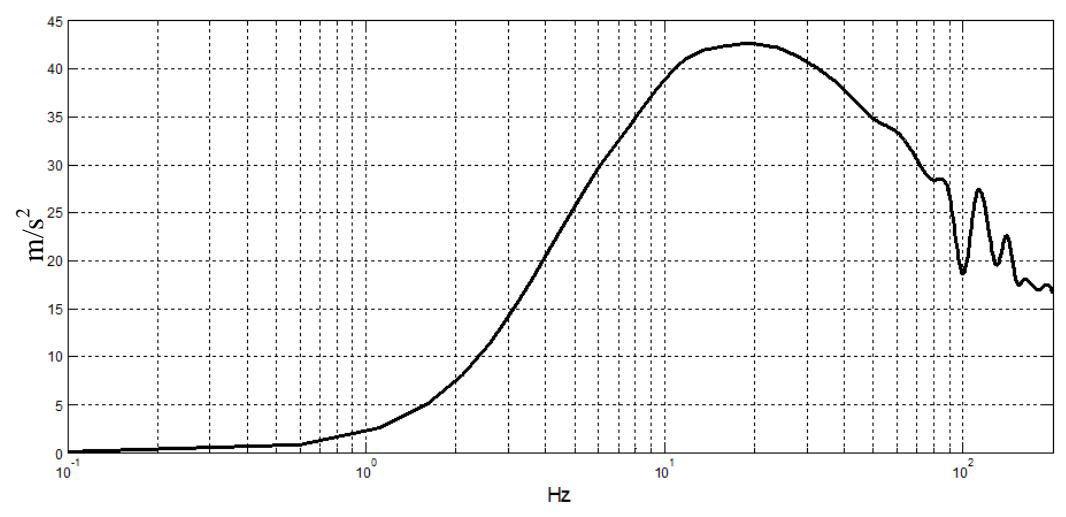

Figure 2. Acceleration Amplitude-Frequency Characteristic Curve of Horizontal Shaking Table under Open Loop Situation

According to the figure 2, vibration table there is a resonance peak, the causes of the formant is feedback after feedback circuit and coil inductance coupling. The coil inductance is bigger, the corresponding frequency of resonant point is lower; Coil inductance is smaller, the frequency corresponding to the resonance peak point is bigger, resonant peak is lower. In the actual feedback circuit is designed by increasing the firstorder low-pass filter circuit. That can eliminate the resonant peak.

\section{Frequency Response Function Test}

Amplitude frequency characteristics is one of the important indicators, using Jacqueline Nottingham - 06 type quartz flexible accelerometer in acceleration signals of shaking table, using the relative velocity meter measurement of shaking table in velocity signal of shaking table, Amplitude-frequency response characteristic of horizontal shaking table under open loop situations as shown in table 2. 
Table 2. Amplitude-Frequency Response Characteristic of Horizontal Shaking Table under Open Loop Situation

\begin{tabular}{llcl}
\hline $\begin{array}{l}\text { Frequency } \\
(\mathrm{Hz})\end{array}$ & $\begin{array}{l}\text { Input voltage } \\
(\text { Vo-p })\end{array}$ & $\begin{array}{l}\text { Acceleration } \\
\text { output voltage }(\mathrm{V})\end{array}$ & $\begin{array}{c}\text { Speed output } \\
\text { voltage }(\mathrm{A})\end{array}$ \\
\hline 0.5 & 0.1 & 0.0077 & 1.87 \\
0.8 & 0.1 & 0.0175 & 2.98 \\
1 & 0.1 & 0.0270 & 3.68 \\
2 & 0.1 & 0.0937 & 6.82 \\
3 & 0.1 & 0.1895 & 9.28 \\
5 & 0.05 & 0.162 & 5.02 \\
8 & 0.05 & 0.230 & 4.37 \\
10 & 0.05 & 0.245 & 3.85 \\
15 & 0.1 & 0.532 & 5.510 \\
20 & 0.1 & 0.535 & 4.168 \\
30 & 0.1 & 0.513 & 2.623 \\
40 & 0.1 & 0.476 & 1.813 \\
50 & 0.1 & 1.427 & 1.313 \\
60 & 0.1 & 1.358 & 1.095 \\
70 & 0.1 & 1.242 & 0.833 \\
80 & 0.2 & 2.312 & 1.376 \\
90 & 0.2 & 2.171 & 1.148 \\
100 & 0.2 & 1.513 & 0.664 \\
110 & 0.2 & 2.164 & 0.781 \\
120 & 0.2 & 1.986 & 0.712 \\
130 & 0.2 & 1.591 & 0.515 \\
140 & 0.2 & 1.841 & 0.358 \\
150 & 0.2 & 1.471 & 0.399 \\
160 & 0.2 & 1.467 & 0.419 \\
170 & 0.2 & 1.426 & 0.307 \\
180 & 0.2 & 1.381 & 0.264 \\
190 & 0.2 & 1.425 & 0.273 \\
200 & 0.2 & 1.342 & 0.295 \\
\hline
\end{tabular}

Notes: for measuring acceleration, using piezoelectric accelerometer above $50 \mathrm{~Hz}$ (including it), the sensitivity of $0.407 \mathrm{~V} / \mathrm{m} / \mathrm{s} 2,40 \mathrm{~Hz}$ (below) using quartz flexible accelerometer, the sensitivity of $0.126 \mathrm{~V} / \mathrm{m} / \mathrm{s} 2$. For measuring velocity, the use of vibration velocity meter is with the sensitivity of $123 \mathrm{v} / \mathrm{m} / \mathrm{s}$.

According to table 3, under the same excitation, horizontal direction of the shaking table with open-loop condition is under $1 \mathrm{vp}-\mathrm{p}$ input voltage equivalent acceleration and equivalent velocity.

It is shown in table 3.

So we can get the acceleration amplitude-frequency characteristic curve as shown in Figure 5 .

After using the closed-loop feedback control, it tests the amplitude-frequency characteristics of shaking table horizontally.

It is shown in table 4.

And we can get table 5. According to table 5, by interpolation, can horizontal direction of the shaking table of acceleration amplitude frequency characteristic curve of closedloop conditions, as shown in figure 3. 
Table 3. Equivalent Output with 1Vp-P Exciter of Horizontal Shaking Table under Open Loop Situation

\begin{tabular}{ccc}
\hline Frequency $(\mathrm{Hz})$ & Acceleration $(\mathrm{m} / \mathrm{s} 2)$ & Speed $(\mathrm{m} / \mathrm{s})$ \\
\hline 0.5 & 0.6032 & 0.15285 \\
0.8 & 1.4682 & 0.24147 \\
1 & 2.2222 & 0.29836 \\
2 & 7.4444 & 0.55367 \\
3 & 14.246 & 0.75366 \\
5 & 25.713 & 0.81463 \\
8 & 34.921 & 0.71220 \\
10 & 38.889 & 0.62602 \\
15 & 42.222 & 0.44797 \\
20 & 42.530 & 0.33887 \\
30 & 40.713 & 0.21325 \\
40 & 37.778 & 0.14732 \\
50 & 34.816 & 0.10683 \\
60 & 33.366 & 0.08911 \\
70 & 30.516 & 0.06772 \\
80 & 28.403 & 0.05594 \\
90 & 26.793 & 0.04671 \\
100 & 18.587 & 0.02698 \\
110 & 26.572 & 0.03171 \\
120 & 24.423 & 0.02894 \\
130 & 19.558 & 0.02094 \\
140 & 22.629 & 0.01455 \\
150 & 18.084 & 0.01622 \\
160 & 18.033 & 0.01699 \\
170 & 17.531 & 0.01244 \\
180 & 16.978 & 0.01077 \\
190 & 17.518 & 0.01106 \\
200 & 16.473 & 0.01198 \\
\hline & & \\
\hline
\end{tabular}

Table 4 .Amplitude Versus Frequency Characteristic of Horizontal Shaking Table under Closed Loop Situation

\begin{tabular}{cccc}
\hline Frequency $(\mathrm{Hz})$ & Input signal $(\mathrm{Vp}-\mathrm{p})$ & Acceleration $(\mathrm{m} / \mathrm{s} 2)$ & Speed $(\mathrm{m} / \mathrm{s})$ \\
\hline 0.1 & 0.5 & $/$ & 0.0034 \\
0.2 & 1.0 & $/$ & 0.0077 \\
0.3 & 1.0 & 0.041 & 0.0082 \\
0.5 & 1.5 & 0.093 & 0.0130 \\
0.8 & 2 & 0.123 & 0.0184 \\
1 & 2 & 0.350 & 0.0197 \\
2 & 2 & 0.712 & 0.0280 \\
3 & 2 & 1.907 & 0.0380 \\
5 & 2 & 1.273 & 0.0613 \\
8 & 0.5 & 2.117 & 0.0253 \\
10 & 0.5 & 1.271 & 0.0338 \\
15 & 0.1 & 4.494 & 0.0134 \\
20 & 0.1 & 4.813 & 0.0356 \\
30 & 0.1 & 5.335 & 0.0255 \\
40 & 0.2 & 4.155 & 0.0202 \\
50 & 0.2 & 3.694 & 0.0123 \\
60 & 0.2 & 3.302 & 0.0093 \\
70 & 0.2 & 3.075 & 0.0074 \\
80 & 0.2 & & 0.0058 \\
\hline
\end{tabular}




\begin{tabular}{cccc}
\hline 90 & 0.2 & 3.052 & 0.0051 \\
100 & 0.2 & 2.826 & 0.0042 \\
110 & 0.2 & 2.644 & 0.0036 \\
120 & 0.2 & 2.534 & 0.0035 \\
\hline
\end{tabular}

Table 5. Equivalent Output with the Same Exciter of Horizontal Shaking Table under Closed Loop Situation

\begin{tabular}{ccc}
\hline Frequency $(\mathrm{Hz})$ & Acceleration $(\mathrm{m} / \mathrm{s} 2)$ & Speed $(\mathrm{m} / \mathrm{s})$ \\
\hline 0.1 & $/$ & 0.0068 \\
0.2 & $/$ & 0.0077 \\
0.3 & 0.027 & 0.0082 \\
0.5 & 0.046 & 0.0088 \\
0.8 & 0.062 & 0.0093 \\
1 & 0.175 & 0.0098 \\
2 & 0.356 & 0.0140 \\
3 & 0.954 & 0.0190 \\
5 & 2.546 & 0.0306 \\
8 & 4.235 & 0.0509 \\
10 & 12.70 & 0.0677 \\
15 & 44.94 & 0.1346 \\
20 & 48.13 & 0.3563 \\
30 & 26.66 & 0.2546 \\
40 & 20.77 & 0.1010 \\
50 & 18.48 & 0.0621 \\
60 & 16.52 & 0.0464 \\
70 & 15.38 & 0.0372 \\
80 & 15.26 & 0.0294 \\
90 & 14.13 & 0.0258 \\
100 & 13.22 & 0.0212 \\
110 & 12.68 & 0.0179 \\
120 & & 0.0173 \\
\hline
\end{tabular}

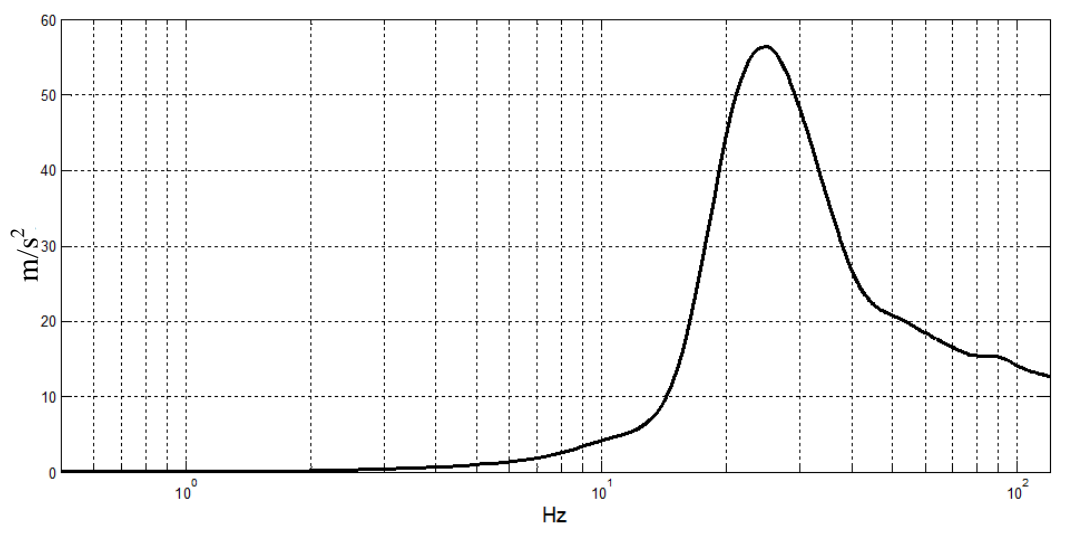

Figure 3. Acceleration-Amplitude versus Frequency Characteristic Curve of Horizontal Shaking Table under Closed Loop Situation 


\section{Distortion Measurement}

According to the harmonic analysis method $[4,5]$, the results are shown in table 6 :

Table 6. Distortion Test Result of Horizontal Shaking Table

\begin{tabular}{|c|c|c|c|c|c|c|c|c|c|c|c|c|}
\hline \multicolumn{2}{|c|}{ Frequency $(\mathrm{Hz})$} & 0.1 & 0.2 & 0.3 & 0.5 & 0.8 & 1 & 2 & 3 & 5 & 8 & 16 \\
\hline \multirow{4}{*}{$\begin{array}{l}\widehat{o} \\
\stackrel{0}{0} \\
. \frac{0}{ \pm} \\
\frac{0}{0} \\
\frac{0}{0}\end{array}$} & $\begin{array}{l}\text { Open loop } \\
\text { acceleration }\end{array}$ & I & I & I & 89.0 & 52.7 & 41.2 & 18.8 & 6.88 & 0.90 & 0.48 & 0.45 \\
\hline & $\begin{array}{l}\text { Open loop } \\
\text { speed }\end{array}$ & / & / & I & 46.9 & 21.9 & 13.8 & 6.48 & 2.32 & 0.14 & 0.32 & 0.24 \\
\hline & $\begin{array}{l}\text { Closed loop } \\
\text { acceleration }\end{array}$ & l & l & l & 6.71 & 5.39 & 4.84 & 3.70 & 3.33 & 2.18 & l & l \\
\hline & $\begin{array}{l}\text { Closed loop } \\
\text { speed }\end{array}$ & 6.68 & 4.73 & 3.76 & 2.66 & 2.25 & 2.06 & 1.42 & 0.96 & 0.43 & I & 1 \\
\hline \multicolumn{2}{|c|}{ Frequency (Hz) } & 20 & 30 & 40 & 50 & 60 & 70 & 80 & 90 & 100 & 110 & 120 \\
\hline \multirow{4}{*}{$\begin{array}{l}\frac{0}{0} \\
\frac{0}{0} \\
\frac{0}{t} \\
\frac{0}{0} \\
\frac{0}{0}\end{array}$} & $\begin{array}{l}\text { Open loop } \\
\text { acceleration }\end{array}$ & 0.36 & 0.30 & 0.39 & 0.51 & 0.46 & 0.90 & 0.72 & 0.95 & 0.69 & 0.77 & 2.29 \\
\hline & $\begin{array}{l}\text { Open loop } \\
\text { speed }\end{array}$ & 0.23 & 0.61 & 0.49 & 0.31 & 0.53 & 1.62 & 1.47 & 1.66 & 1.80 & 0.68 & 20.5 \\
\hline & $\begin{array}{l}\text { Closed loop } \\
\text { acceleration }\end{array}$ & l & l & I & l & l & l & l & l & l & l & I \\
\hline & $\begin{array}{c}\text { Closed loop } \\
\text { speed }\end{array}$ & I & I & I & I & 1 & I & 1 & 1 & I & 1 & 1 \\
\hline
\end{tabular}

According to the test results, after adding feedback, vibration distortion decreased significantly, The motion signal quality is improved, This method can meet the general needs of low frequency vibration sensor calibration.

\section{Fund Project Support}

The work was supported by Science and Technology Research and Development Fund of Langfang Science \& Technology Bureau (No.2014011062); Scientific Research Plan Projects for Higher Schools in Hebei Province (No. QN2014313); The Special Fund of Fundamental Scientific Research Business Expense for Higher School of Central Government (Projects for creation teams) (No. ZY20110104).

\section{Acknowledgements}

In the process of writing this paper, I got a lot of help.

First of all, thanks to Dr. Qinglei Chi (Institute of engineering mechanics, China Earthquake Administration), Provided me with a lot of experimental data and have a guide to my thesis; Second, thanks to my student Qiuchen Li, He checked and corrected my thesis translation; At last, thanks to my colleague Juan meng, She made the necessary changes to the format and composition of the paper. Here I express my gratitude to all who helped me.

Thank you for the scholars involved in this thesis. I drew on the research literature of a number of scholars, I would be very difficult to complete the writing without the help and Inspiration of the research results of the scholars.

Because of my limited academic standards, there are some shortcomings unavoidable, welcome to point it out. 


\section{References}

[1] Department of Seismic Hazard Prevention, China Earthquake Administration. Uncorrected Acceleration of the Ms 8.0 Wenchuan Earthquake, (2008), Seismological Press, Beijing.

[2] C.H. Zhou, "The strong ground motion recordings of the Ms8.0 Wenchuan Earthquake in Sichuan Province", vol. 4, no. 129, (2008), pp. 25-29, Earthquake Research in Sichuan.

[3] Y. Qiaoyu and S. Yulong, "Discussion on measurement methods for specification of low frequency calibration shaking table", world earthquake engineering, vol. 24, no. 2, (2008), pp. 97-101.

[4] X.F. Yuan, H.L. Xu and S.H. Chen, "Comment on Measurement Methods of Sinusoidal Signal Distorted Degree", Aviation Metrology \& Measurement Technology, vol. 24, no. 1, (2004), pp. 1-3.

[5] Z.G. Liang, J.J. Zhu and J.Y. Sun, "A Precise Evaluation Method for the Distortion of Sinusoidal Sources”, Acta Metrologica Sinica, vol. 24, no. 2, (2003), pp. 144-148.

\section{Authors}

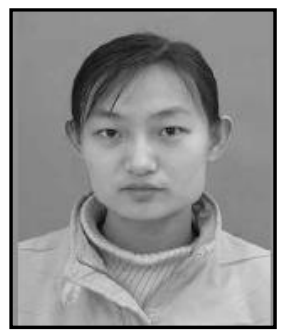

Lina Cheng, She was born in 1983. She received her master degree circuit and system in 2008, graduated from Beijing Jiaotong University. Now she is full-time teacher of Institute of Disaster Prevention. Her current research interests include research and application of sensor technology. 
International Journal of Control and Automation Vol. 9, No. 3 (2016) 